\title{
Visiones y tensiones sobre el debate de los transgénicos en el Ecuador
}

\section{Visions and tensions on the debate on transgenics in Ecuador}

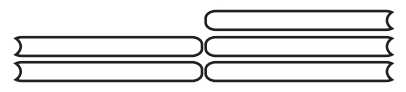

Elizabeth Bravo ${ }^{1}$

Recibido: enero 2017 Aprobado: junio 2017

\section{Resumen}

Desde que se declaró al Ecuador libre de transgénicos, se ha desatado en el país un debate muy polarizado entre quienes defienden esta declaración y los que defienden la aplicación de la biotecnología en el agro. Este debate ha incluido a distintos sectores de la sociedad, incluyendo la academia, las organizaciones campesinas, de público consumidor y el propio Estado. Este artículo recoge las principales narrativas que surgen en torno a esta problemática, especialmente durante los años, cuando el presidente de la República hizo un llamado a la sociedad, especialmente académica a pronunciarse sobre el tema.

Palabras clave: Análisis de narrativas, cultivos transgénicos, riesgos, prohibición constitucional, Ecuador.

\begin{abstract}
Since Ecuador was declared a GE Free country, a very polarized debate has been taking place, between those who defend this declaration and those who defend the application of biotechnology in agriculture. This debate has included different sectors of society, including academia, peasant organizations, consumers and the state itself. This article gathers the main narratives that arise around this problematic, especially during the years, when the President of the Republic made a call to the society, especially academy, to debate on this matter.
\end{abstract}

Kew words: Narratives analysis, GM crops, risks, Constitutional ban, Ecuador

$1 \quad$ Universidad Politécnica Salesiana. Red por una América Latina Libre de Transgénicos. mbravov@ups.edu.ec 


\section{Antecedentes}

En el año 2008 se produjo en el Ecuador un cambio constitucional muy importante. En esta nueva Constitución, se reconocieron derechos a la naturaleza; se declaró que el plan de desarrollo debe estar basado en el "buen vivir" o Sumak Kawasay, que implica una nueva relación entre los seres humanos entre sí, y con la naturaleza; se declaró como prioridad del Estado la soberanía alimentaria, y se declaró al país "libre de semillas y cultivos transgénicos” (Art. 401 de la Constitución). Entre los aspectos relacionados con los derechos ambientales, se estableció una prohibición a los organismos genéticamente modificados que puedan ser perjudiciales para la salud humana o que atenten contra el patrimonio genético y la soberanía alimentaria (Art. 15), y se prohibió la introducción al país de organismos que puedan alterar de manera definitiva el patrimonio genético nacional (Art. 73), así como las tecnologías peligrosas y experimentales (Art. 401).

Sin embargo, se abrió la posibilidad de que el presidente de la República, excepcionalmente y solo por razones de interés nacional, podría abrir la posibilidad de liberar cultivos transgénicos en el país.

La presión sobre este tema ha sido muy grande en el Ecuador, como lo revela un wikileak, en el que un cable de la Embajada de Estados Unidos afirma que el sector agronegocio nacional ejerció una fuerte presión durante la redacción de la nueva Constitución ecuatoriana, en relación con el tema de los cultivos transgénicos.

En septiembre 2012, cuatro años después de adoptada la nueva Constitución, el presidente de la República Rafael Correa dijo que fue un error la prohibición constitucional a los cultivos y semillas transgénicas, y llamó a un debate nacional liderado por la Secretaría de Ciencia y Tecnología (SENACYT). A partir de entonces, se dieron una serie de debates, foros, conferencias en varias universidades y centros académicos del país, así como entre organizaciones de la sociedad civil preocupada por el tema. El tema continuó debatiéndose arduamente en los meses siguientes.

Este artículo pretende analizar las principales narrativas que surgieron en torno a esta problemática, y a cómo se encuadra el debate sobre los transgénicos en el Ecuador, a partir de las declaraciones presidenciales sobre el tema.

Para ello se eligieron las principales tensiones identificadas en dos libros que surgieron de ese debate, los que muestran puntos de vistas opuestos: "Los transgénicos, una cuestión científica” y "Transgénicos, la inconciencia de la 
ciencia”. Se analizan además otras publicaciones de ese período, con el fin de brindar una visión de otros actores que participaron en este debate nacional.

Las tensiones escogidas se presentan en la Tabla 1. Dado que la disposición constitucional habla de "semillas y cultivos transgénicos", gran parte del debate se centra en los transgénicos para la agricultura.

Tabla 1

Tensiones y visiones sobre los transgénicos en Ecuador

\begin{tabular}{|c|c|c|c|}
\hline Las tensiones & El problema & Visiones pro OGM & Visiones anti OGM \\
\hline $\begin{array}{l}\text { El marco legal y } \\
\text { constitucional }\end{array}$ & $\begin{array}{l}\text { Aunque la Constitución } \\
\text { del Ecuador prohíbe } \\
\text { los cultivos y semillas } \\
\text { transgénicos, se ha } \\
\text { planteado enmendarla. }\end{array}$ & $\begin{array}{l}\text { Es necesario normar los } \\
\text { OGM como sucede en } \\
\text { otros países. }\end{array}$ & $\begin{array}{l}\text { Se debe mantener } \\
\text { al Ecuador libre de } \\
\text { transgénicos. }\end{array}$ \\
\hline $\begin{array}{l}\text { El rol de los científicos y } \\
\text { la población en el debate } \\
\text { de los transgénicos }\end{array}$ & $\begin{array}{l}\text { En el Ecuador existe muy } \\
\text { poco entendimiento sobre } \\
\text { los transgénico y sus } \\
\text { peligros. }\end{array}$ & $\begin{array}{l}\text { Son los grupos científicos } \\
\text { los llamados a incidir en } \\
\text { las decisiones sobre el } \\
\text { tema. }\end{array}$ & $\begin{array}{l}\text { La toma de decisiones } \\
\text { sobre los OGM } \\
\text { está atravesada por } \\
\text { relaciones de poder y son } \\
\text { inminentemente políticas. }\end{array}$ \\
\hline $\begin{array}{l}\text { La incertidumbre } \\
\text { científica sobre los } \\
\text { transgénicos }\end{array}$ & $\begin{array}{l}\text { No existe certidumbre } \\
\text { científica sobre los } \\
\text { impactos de los } \\
\text { transgénicos. } \\
\end{array}$ & $\begin{array}{l}\text { Los OGM son cada vez } \\
\text { más seguros. }\end{array}$ & $\begin{array}{l}\text { Cada vez hay un mayor } \\
\text { número de estudios que } \\
\text { demuestran los impactos } \\
\text { de los transgénicos. } \\
\end{array}$ \\
\hline $\begin{array}{l}\text { Los transgénicos y la } \\
\text { biodiversidad }\end{array}$ & $\begin{array}{l}\text { El Ecuador es un país rico } \\
\text { en agrobiodiversidad. }\end{array}$ & $\begin{array}{l}\text { Hay que explotar una } \\
\text { biotecnología basada en } \\
\text { nuestra biodiversidad. }\end{array}$ & $\begin{array}{l}\text { La gran biodiversidad del } \\
\text { Ecuador puede estar en } \\
\text { riesgo con la introducción } \\
\text { de organismos } \\
\text { transgénicos. }\end{array}$ \\
\hline $\begin{array}{l}\text { Los transgénicos y la } \\
\text { agricultura }\end{array}$ & $\begin{array}{l}\text { La productividad agrícola } \\
\text { en el Ecuador es muy } \\
\text { baja, especialmente en la } \\
\text { región interandina. }\end{array}$ & $\begin{array}{l}\text { Los cultivos transgénicos } \\
\text { pueden solucionar } \\
\text { muchos de los problemas } \\
\text { agronómicos del país. }\end{array}$ & $\begin{array}{l}\text { Se debe apoyar la } \\
\text { investigación en prácticas } \\
\text { agroecológicas y dar más } \\
\text { apoyo a la producción } \\
\text { campesina. }\end{array}$ \\
\hline $\begin{array}{l}\text { Los transgénicos y la } \\
\text { salud humana }\end{array}$ & $\begin{array}{l}\text { Los desarrollos } \\
\text { biotecnológicos en el } \\
\text { campo de la salud van a } \\
\text { salvar millones de vidas. }\end{array}$ & $\begin{array}{l}\text { El Estado debe invertir en } \\
\text { ciencia y tecnología en el } \\
\text { área de biotecnología en } \\
\text { el campo de la salud. }\end{array}$ & $\begin{array}{l}\text { Tanto los OGM como } \\
\text { el paquete tecnológico } \\
\text { asociado, son riesgosos } \\
\text { para la salud. }\end{array}$ \\
\hline
\end{tabular}

\section{El corpus}

Para visibilizar las tensiones sobre los cultivos transgénicos se hizo un análisis de las narrativas plasmadas en un grupo de textos publicados entre finales del 2012 e inicios del 2015, período en el que perduró el debate iniciado por el presidente de la República. En una primera instancia se eligieron publicaciones desde el círculo académico, dada la gran producción generada en ese período y porque permiten develar las principales contradicciones en torno a este tema. Posteriormente, se recogen declaraciones de los movimientos sociales, realizadas también en el período analizado. 
De lo publicado en los círculos académicos, se escogió un grupo de textos que reflejan las distintas posiciones que emergieron. Se trató de ubicar posiciones provenientes del sector oficial (incluyendo un experto de una organización internacional), la sociedad científica, la prensa y el mundo científico, diferenciando las ciencias sociales de las biológicas.

El análisis se circunscribe al debate en torno a las aplicaciones de la biotecnología en la agricultura.

Tabla 2

Los voceros sobre los transgénicos en el Ecuador

\begin{tabular}{|c|c|c|}
\hline Sector & Vocero & Publicación \\
\hline \multirow[t]{2}{*}{$\begin{array}{l}\text { La sociedad científica } \\
\text { (desde las ciencias sociales) }\end{array}$} & $\begin{array}{l}\text { Edgar Isch. } \\
\text { Docente de la Facultad de } \\
\text { Agronomía. } \\
\text { Universidad Central del } \\
\text { Ecuador } \\
\end{array}$ & $\begin{array}{l}\text { Las nefastas consecuencias } \\
\text { de los transgénicos para las } \\
\text { políticas públicas. }\end{array}$ \\
\hline & $\begin{array}{l}\text { Nicolás Cuvi } \\
\text { (Profesor investigador del } \\
\text { Programa de Desarrollo, } \\
\text { Ambiente y Territorio } \\
\text {-FLACSO) }\end{array}$ & $\begin{array}{l}\text { Hegemonías culturales e } \\
\text { impertinencias metodológicas: } \\
\text { Reflexiones en torno a la } \\
\text { potencial introducción de } \\
\text { transgénicos en el agro } \\
\text { ecuatoriano }\end{array}$ \\
\hline \multirow[t]{2}{*}{$\begin{array}{l}\text { La sociedad científica } \\
\text { (desde las ciencias naturales) }\end{array}$} & $\begin{array}{l}\text { César Paz y Miño. } \\
\text { (Decano del Instituto de } \\
\text { Investigaciones Biomédicas. } \\
\text { Universidad de las Américas) }\end{array}$ & $\begin{array}{l}\text { Transgénicos: una cuestión } \\
\text { científica (compilación de } \\
\text { artículos). UDLA. }\end{array}$ \\
\hline & $\begin{array}{l}\text { Efrén Santos. } \\
\text { (Investigador de la Escuela } \\
\text { Politécnica del Litoral. Trabaja } \\
\text { en el desarrollo de banano } \\
\text { transgénico) } \\
\end{array}$ & $\begin{array}{l}\text { Retos de la ingeniería genética } \\
\text { del banano en el Ecuador: } \\
\text { resistencia a la sigatoka negra } \\
\text { y otras aplicaciones. En: Los } \\
\text { transgénicos y la salud. UDLA } \\
\end{array}$ \\
\hline La prensa & $\begin{array}{l}\text { Gonzalo Ortiz } \\
\text { (Editor Jefe de la Revista } \\
\text { Gestión) }\end{array}$ & $\begin{array}{l}\text { Biotecnología: las } \\
\text { contradicciones del modelo. } \\
\text { Revista Gestión No. 214. } 2012 .\end{array}$ \\
\hline \multirow[t]{2}{*}{ Organizaciones agroecológicas } & Movimiento agroecológico & $\begin{array}{l}\text { Agrobiotecnología: las voces } \\
\text { opuestas. Revista Gestión. No. } \\
217.2012 .\end{array}$ \\
\hline & $\begin{array}{l}\text { Javier Carrera } \\
\text { Red de Guardianes de Semillas }\end{array}$ & Los transgénicos - en debate \\
\hline Organismos internacionales & $\begin{array}{l}\text { Julio Escobar (especialista en } \\
\text { bioseguridad y biotecnología } \\
\text { del IICA) }\end{array}$ & $\begin{array}{l}\text { Biotecnología, bioseguridad y } \\
\text { agricultura. Los transgénicos y } \\
\text { la salud }\end{array}$ \\
\hline Sector oficial & \begin{tabular}{|l|} 
Joy Woolfson \\
Experta del Ministerio del \\
Ambiente \\
\end{tabular} & $\begin{array}{l}\text { Biotecnología, Organismos } \\
\text { Genéticamente Modificados y } \\
\text { Bioseguridad. }\end{array}$ \\
\hline
\end{tabular}




\section{El marco legal y constitucional}

Mientras en América Latina hay un crecimiento vertiginoso de los cultivos transgénicos, el Ecuador se declara libre de transgénicos.

Gonzalo Ortiz

Desde el pronunciamiento del presidente del Ecuador, donde plantea la necesidad de hacer una enmienda constitucional sobre la prohibición a los cultivos transgénicos, varios sectores se pronunciaron a favor de que haya cambios en la Constitución, y que el tema se trate vía regulación, y se pide un apego a la Constitución vigente.

A partir de la declaración, se comenzaron a escribir políticas públicas que actuaban como si los transgénicos no estuvieran prohibidos, por ejemplo, en el llamado Plan Nacional del Buen Vivir 2013 - 2017, que es lo correspondiente a un plan nacional de planificación. Al respecto, el periodista Gonzalo Ortiz (2012), después de reconocer que el PNBV está en contradicción con la Constitución, pues señala a la biotecnología como uno de los 10 áreas prioritarias para el desarrollo del país, añade que este plan "reconoce que es la biotecnología donde existe la esperanza de enormes ganancias, a condición de que los riesgos ligados a esas innovaciones no deben ser asumidos en el presente ni en el futuro por los actores de la acumulación económica" y concluye señalando que el plan "pide desarrollar normas de bioseguridad en cumplimiento del principio de precaución” (p. 12).

Es notoria, además, la posición de la representante del Ministerio del Ambiente, Joy Woofson (2013) "frente a los riesgos, es mandatorio que, para realizar cualquier actividad con $\mathrm{OGM}^{2}$, se cumplan con normas de bioseguridad", por lo que "el Ministerio del Ambiente está empeñado en poner en marcha un Sistema Nacional de Bioseguridad” (p. 78).

El investigador Efrén Santos (2013), responsable del desarrollo del banano transgénico, dijo que "La ingeniería genética debe ser regulada en el país, pero no prohibida, ya que existen varias aplicaciones, que deben ser enfocadas para solucionar los problemas del país en el ámbito agropecuario e industrial”. Él, además, señaló que no hay claridad en la Constitución en el tema de la investigación, y que...

2 Organismos genéticamente modificados 
debido a la falta de un marco regulatorio, el artículo (401), no prohíbe en primera instancia la investigación sobre transgénicos. Sin embargo, es indispensable que exista un marco regulatorio de los transgénicos en el país que cubra los aspectos de investigación, incluyendo pruebas en invernaderos y campo; y asimismo, en la liberación de transgénicos al ambiente. (Santos, 2013, p. 79)

A él también le preocupa que hay un vacío en el tema de la investigación biotecnológica: "El Art. 401 de la Constitución no prohíbe en primera instancia la investigación sobre transgénicos. Sin embargo, es indispensable que exista un marco regulatorio de los transgénicos en el país que cubra los aspectos de investigación" (p. 81).

Santos defiende "La libertad de investigación en biotecnología", y dice que "según el artículo 401 de la Constitución se prohíben solo "aquellas riesgosas y experimentales" (Santos, 2013).

Entre los que defienden el texto constitucional está Nicolás Cuvi (2014), quien dice que "es necesario promover una ciencia y una tecnología que vayan de la mano con nuestra Constitución vigente, que fomenten el desarrollo endógeno, soberano, sostenible, y no la perpetuación de la dependencia en corporaciones que controlan la tecnología y los mercados" (p. 75).

Uno de los sectores que más defiende la Carta Constitucional es el Colectivo Agroecológico, que está formado por un grupo de productores agroecológicos y grupos de consumidores y organizaciones no gubernamentales que defienden la alimentación sana.

La Constitución de Montecristi es la más legítima que ha tenido este país, no sólo por la inmensa participación y consenso social que se construyó alrededor de ella, sino además porque el 64\% del pueblo ecuatoriano la aceptó mediante un referéndum constitucional, por lo que estos principios ahí consagrados deben ser respetados. (Colectivo Agroecológico, 2012, p. 20)

Por su parte, Julio Escobar, experto en bioseguridad de la oficina del IICA en Ecuador, ignorando por completo el texto constitucional señala:

Para aprobar o prohibir un determinado cultivo transgénico, éste se lo debe analizar con un enfoque "caso por caso" y "paso a paso". Significa que no se pude generalizar cuando se habla de transgénicos, cada transgénico es diferente y tiene sus especificidades en función del evento 
desarrollado, de la aplicación o mojera implementada, y del sitio al cual se va a destinar su uso. (Escobar, 2012, p. 14)

$\mathrm{Y}$ al referirse a la normativa ecuatoriana en bioseguridad Escobar considera que hay una gran ambigüedad entre lo que plantean los marcos normativos con las políticas que se están desarrollando en torno a este tema, lo que produce poca claridad para el sector productivo.

\section{Los transgénicos: Una cuestión científica}

En el debate sobre los transgénicos en el Ecuador, uno de los temas que surge con mucha fuerza es que es la ciencia la que debe dirimir las tensiones relacionadas con los riesgos que podrían emerger de las aplicaciones biotecnológicas, y más específicamente del uso de semillas transgénicas. Dado que la complejidad relacionada con su construcción es tan grande, solo un pequeño grupo de iniciados lo entiende, y es ese grupo quien debe dar su opinión y construir normas relacionadas con el tema. Y con esa visión la Secretaría de Educación Superior (SENACYT) organizó sus consultas sobre el tema.

Una crítica a esa perspectiva fue hecha por Bravo (2012, p. 80), quien describe así el proceso de consulta:

La respuesta del SENACYT fue convocar a un grupo de científicos “duros” para debatir el tema de los transgénicos, con un público formado en la mayoría de casos por estudiantes de biotecnología o ciencias de la vida. Muchos de los ponentes se manifestaron la necesidad de que se haga investigación en transgénicos en el país, usando argumentos como que nos vamos a queda por afuera del tren del progreso; que los principales journal científicos sólo publican artículo que incluyan herramientas procedentes de la biología molecular o sobre la necesidad de tener una ciencia "autónoma".

Esta es la posición mantenida por los representantes del gobierno, del IICA y de la prensa (Escobar, 2012; Ortiz, 2012; Woolfson 2012), quienes citan un análisis hecho por el Ministerio del Ambiente ${ }^{3}$, donde se encontró que el $80 \%$ de la población no cuente con suficiente información sobre lo que son los transgénicos, no conocen su significado y, por lo mismo, no deben pronunciarse al respecto, $y$ añaden que quienes se oponen a los transgénicos lo hacen dogmáticamente, pues desconocen los complicados procesos genéticos complicados que se necesitan para desarrollarlos, y "desvían la atención

3 En 2007, el Ministerio del Ambiente hizo un estudio de la percepción pública sobre los OGM, biotecnología y bioseguridad en 10 ciudades del país. 
al plano político, ideológico y retórico" (Paz y Miño, 2013, p. 40). No hay lugar para consideraciones de carácter político o ideológico entre los que suscriben esta posición, pues "los transgénicos son una cuestión científica".

Para Julio Escobar (2012, p. 20), experto del IICA los países pueden tomar decisiones soberanas sobre los cultivos transgénicos, pero estas deben se informadas y basadas en la ciencia.

Una posición diferente mantienen otros investigadores como Nicolás Cuvi (2014), quien señala que "no podemos, con ingenuidad científica y ambiental, considerar que la tecnología es algo ajeno a los asuntos cotidianos, que es una esfera en la que tienen acción únicamente quienes controlan ciertos lenguajes y técnicas; no podemos dejar estas reflexiones solamente en manos de ingenieros o biotecnólogos, que actúan sin conocer los contextos sociales, económicos y ambientales; en suma, sin enfoques de pertinencia”.

En este debate se han generado reflexiones en torno a las relaciones de poder que atraviesan a la ciencia; por eso, aunque se sostiene que la comunidad científica es la llamada a tomar decisiones sobre ciencia y tecnología, dentro de ella también se reflejan esas relaciones de poder. Es así como hay científicos que generan evidencias à la carte respondiendo a la demanda de sus auspiciantes, lo que Breilh (2008) llama "ciencia por contrato".

Nicolás Cuvi (2014, p. 70) también cuestiona la neutralidad de la ciencia, pues la ciencia que logra posicionarse es "aquella de interés para quienes ejercen hegemonía", y nos recuerda que el Ecuador es un país que ha sido construido "sobre la base de relaciones de carácter colonial y perversas exclusiones que operan a distintos niveles de complejidad, mediante la construcción de hegemonías locales, estatales, nacionales, regionales, a escala internacional y global".

Paz y Miño (2015) responde que para enfrentar estas relaciones coloniales, que se extienden también a la ciencia, "es necesario hacer más investigación soberana, para saber qué producto transgénico es bueno o no para el país"; sin embargo, Isch (2014) sostiene que, siendo el Ecuador un país dependiente, los desarrollos tecnológicos que emerjan de la agrobiotecnología estarán destinados al sector agroexportador, o a la producción de alimentos interna controlada por un pequeño grupo de empresas, por lo que el uso de transgénicos permitirá que estas empresas dirijan la producción de alimentos básicos en el país.

Julio Escobar (2012) del IICA defiende una investigación científica nacional y hecha por empresas estatales. Señala como ejemplo el caso del fréjol 
resistente al virus del mosaico dorado desarrollado en Brasil por EMBRAPA, que responde a una problemática específica de ese país. Esta es una posición compartida por otras organizaciones internacional como la FAO, pero es anacrónica pues, si bien el Estado ocupó un papel predominante en promover la Revolución Verde, es un actor marginal en la Revolución Biotecnológica. Una prueba de ello es que mientras en Brasil hay millones de hectáreas sembradas con semillas transgénicas de Monsanto, tres años después de las declaraciones de Escoba, no hay ni una sola hectárea sembrada a nivel comercial, con el fréjol de EMBRAPA.

\section{Los transgénicos: La inconciencia de la ciencia}

Otro tema que está en el centro del debate sobre los transgénicos son los relacionados con la incertidumbre científica que los rodea.

Quienes defienden la biotecnología minimizan los impactos que pueden producir los transgénicos.

Para Paz y Miño (2013) “el desarrollo científico actual ha producido un gran salto en las herramientas que permiten transformar el ambiente macro y micro, al punto de modificar moléculas, el ADN". Complementa su idea sosteniendo que "la biotecnología usada para producir transgénicos es cada vez más efectiva y segura. La metodología es tan compleja, que es imposible que un gen de un producto transgénico por "propia iniciativa" se meta en el ADN del organismo que lo consume” (p. 3).

Joy Woolson (2103) del Ministerio del Ambiente reconoce que hay riesgos asociados a los organismos transgénicos, "sin embrago los que son de debate internacional se centran en los OGMs de uso agrícola y liberación al ambiente". Luego compara los riesgos de los transgénicos con el de "variedades agrícolas mejoradas en forma convencional y en algunos casos cuando se introducen especies exóticas" (p. 77).

Edgar Isch (año, p. 30) sostiene, al contrario, que los transgénicos implican una amenaza a la biodiversidad. Señala que "donde ingresan los transgéni$\cos$, la biodiversidad disminuye. Ello sucede, en parte, debido al fuerte incremento en el uso de agrotóxicos, como glifosato y Roundup, que contaminan gravemente el suelo y las aguas cercanas, con inevitables efectos en insectos, microorganismos y especies mayores", y advierte que los transgénicos afectan la agrobiodiversidad, vía contaminación genética, para lo que pone como el ejemplo lo que ha sucedido con el maíz mexicano, donde se ha entrado contaminación transgénica en variedades nativas. 
En contraste, Julio Escobar (2012, p. 12) dice que "los cultivos transgénicos contribuyen a conservar la biodiversidad, ya que la agrobiotecnología economiza el suelo".

El tema de los riesgos a la salud es tratado de manera muy distinta por los dos grandes grupos identificados aquí. Por un lado, los defensores de la aplicación de la biología molecular al desarrollo tecnológico consideran que los transgénicos son beneficios. Por ejemplo, Paz y Miño (2013, p. 4) sostienen:

Con esta metodología se puede conseguir resistencia a enfermedades, a químicos, producción de enzimas, etc. En organismos pequeños (virus, bacterias) es más fácil el proceso y está bien desarrollado y controlado, por lo cual sus procesos son de uso común (vacunas, hormonas, fármacos, anticuerpos...).

Nicolás Cuvi (2015) analiza la relación de los transgénicos desde dos ámbitos: por un lado se pregunta si debe ser una prioridad para el Ecuador desarrollar medicamentos para la salud mundial (por ejemplo, para tratar diferentes tipos de cáncer), cuando muchos de los problemas en este país están relacionados con las condiciones de vida de la población para lo que se requieren políticas serias de salud pública y muy poco con los medicamentos.

Por otro lado, señala que muchas de las discapacidades que hay en la población están relacionadas con el uso de agroquímicos (que aumentan con la introducción de cultivos transgénicos), por lo que esto "debería constituir una alerta para no perpetuar e incrementar paquetes que causan contaminación y enfermedad, sino formas más eficientes y saludables de producción, que existen y que necesitan ser fortalecidas" (Cuvi, 2015, p. 57).

En el otro frente está el Colectivo Agroecológico, cuyos integrantes relacionan las amenazas de los transgénicos con el incremento en el uso de plaguicidas, y no se limitan solo a los efectos de la modificación genética. Para ello, ponen el ejemplo de Brasil, que se convirtió en el mayor consumidor de pesticidas del mundo, debido al incremento de los cultivos de soja transgénica, donde se usa "el 46\% del veneno total aplicado en plantaciones". Ellos añaden que en Argentina se ha dado también un masivo incremento en el uso de glifosato para el control de malezas en las zonas soyeras del país; y que ahí se vierten más de 200 millones de litros de glifosato por año (Colectivo Agroecológico, 2012). Añaden:

Ha aumentado también el número de intoxicados por el incremento de plaguicidas, así como el presupuesto que los gobiernos tienen que 
invertir en salud pública para atender a sus ciudadanos que enferman por las continuas fumigaciones asociadas a estos cultivos transgénicos. (Colectivo Agroecológico, 2012, p.39)

El Colectivo señala, además, que los problemas de los OGM empiezan con una tecnología que manipula genes, a pesar del gran desconocimiento sobre las interacciones genéticas en los organismos vivos.

Pero permanece el tema de la incertidumbre científica. Por un lado, Julio Escobar (2012) dice que no es posible decir que los transgénicos producen impactos negativos en la salud, y que, en todo caso, hay normativas que se pueden aplicar para evaluar el riesgo y minimizar los impactos negativos. Por su parte, Edgar Isch (2014, p.110) aborda la cuestión de la falta de evidencias científicas sobre los impactos de los transgénicos a la salud humana en estos términos: "En cualquier escenario, incluso el presentado por esas empresas, nadie puede garantizar que los transgénicos son inofensivos para la salud, aún bajo el supuesto de que no existieran evidencias de los daños que causan".

\section{La metáfora de alimentar el mundo y mejorar la vida de la gente}

Otro de los temas en debate es si los transgénicos van a mejorar la producción agrícola, y, por lo mismo, a paliar la falta de alimentos en un mundo cuya población no para de crecer.

Jorge Ortiz (2012, p. 12) considera que "con los cultivos transgénicos se produce más alimentos con menos recursos, pues la producción es más segura al resistir enfermedades y plagas. Incluso hay una reducción de plaguicidas". Julio Escobar (2012) añade que, frente a una población creciente, "los cultivos transgénicos contribuyen a la lucha contra el hambre y la pobreza, a la lucha contra el cambio climático y disminuye la huella ecológica de la agricultura, y considera que el gran potencial que tienen las agrobiotecnologías para enfrentar los grandes retos de la humanidad sólo podrán concretarse con un serio compromiso de cohesión social”.

Por su parte, Edgar Isch (2014, p.120) señala que "La creencia en un enorme poder alimentario, como resultado del uso de unas determinadas semillas, desconoce que enfrentar el hambre involucra muchos aspectos ligados con la lucha por la tierra, como el fomento de mayor trabajo agrícola, que se reduce con los transgénicos y los monocultivos, el necesario reparto de agua con equidad, y los sistemas de comercialización y soportes para que las familias más empobrecidas puedan acceder a la alimentación suficiente y necesaria”. 
Otra pregunta pendiente es si los transgénicos dinamizan la economía rural e incrementan la producción. El Colectivo Agroecológico (2012, p. 43) responde:

Aclaremos: el rendimiento agrícola es la producción dividida para la superficie. La unidad de medida más utilizada es la Tonelada por Hectárea (Tm/Ha). De acuerdo al [sic] economista agrario Javier Rodríguez (2009), en Argentina la soya transgénica no produjo mejores rendimientos, si se compara con la soya convencional, y añade que, aunque la soya transgénica significó que un grupo de empresarios tengan ingresos más altos, hubo una reducción en términos absolutos de la masa salarial involucrada. Por otro lado, en la soya transgénica se emplea apenas a un trabajador cada 225 hectáreas en Argentina.

En esa línea argumentativa, Isch sostiene que el gobierno ecuatoriano ha mantenido que los transgénicos incrementan la productividad, lo que ha sido cuestionado por la Vía Campesina.

En esa misma línea Cuvi (2014, p. 61) reflexiona: "los OGM perpetuarán un secular modelo de apuesta por modos de producir, que acentúan las inequidades e inseguridades nacionales, y generará impactos negativos de índole tecnológica, social, económica y ambiental en las zonas rurales".

No hay que olvidar, señala Isch, que las empresas biotecnológicas tienen un control monopólico sobre las semillas y los insumos agrícolas y advierte que, en los países donde se han adoptado los transgénicos, empresas como Monsanto deja sin opciones a los agricultores, les impone contratos "leoninos" que solo benefician a las empresas.

Otro aspecto de preocupación para el Colectivo Agroecológico es el acaparamiento de tierras, relacionado con la expansión de los cultivos transgénicos.

No es de extrañarse que los países que han adoptado de manera más agresiva los cultivos transgénicos con resistencia a herbicidas sean aquellos donde se registran los niveles más altos de concentración de la tierra. Y es que, al analizar una tecnología, no se puede abstraer del contexto social y económico en la que esta se aplica. No podemos detenernos solamente a evaluar los problemas tecnológicos de los transgénicos (que son muchos), es necesario además tomar en consideración factores como que los cultivos con resistencia a herbicidas son concentradores de tierra, pues las semillas se aplican usando un paquete tecnológico que incluye la llamada de "siembra directa” y la agricultura de precisión que requiere inmensas máquinas, cuya adquisición no se justificaría si no fuera para grandes extensiones. A 
esto hay que sumarle que las aspersiones con herbicidas no permiten la coexistencia con otros cultivos, lo que da como resultado gigantescos monocultivos de cientos de miles de hectáreas.

León (2013) dice que hay una relación directa entre la agroindustria y las semillas transgénicas, ya que estas facilitan la agricultura intensiva, la transformación y distribución para los mercados masivo globales, donde la producción campesina no tiene asidero.

Para Efrén Santos (2013), la ingeniería genética es una herramienta que puede ser usada para la mejora genética de cultivos, como el banano que es muy susceptible a la sigatoka negra a menor tiempo, lo que ayudará a reducir la contaminación y los costos de producción, al evitarse el uso masivo de fungicidas.

El Colectivo Agroecológico responde que debido al desequilibrio ecológico que se genera del modelo productivo basado en semillas transgénicas han emergido nuevos problemas agronómicos, y cita un informe de la Secretaría de Desarrollo Sustentable de Argentina, donde se explica que en las plantaciones de soya transgénica han surgido nuevas enfermedades como la roya de la soja y han proliferado "súper malezas", que ya no pueden ser controladas con glifosato, por lo que se deben usar herbicidas más tóxicos (Secretaría del Ambiente y Desarrollo Sustentable, 2008; citado en Colectivo Agroecológico, 2012). El Colectivo Agroecológico añade que, tanto en Colombia como en la India, los sectores algodoneros, que adoptaron las variedades transgénicas, han sufrido grandes pérdidas, y que en el caso de la India ha tenido un desenlace fatal: un alto número de algodoneros quebrado se ha suicidado.

Una visión complemente distinta es la de Gonzalo Ortiz (2012), quien presenta como ejemplo del éxito de los cultivos transgénicos al algodón Bt en la India y la China. En este último país, señala Ortiz, el algodón se expandió con el impulso de millones de pequeños agricultores, con menos de una hectárea de tierra.

A manera de resumen, Julio Escobar (2012) hace la siguiente reflexión sobre las bondades de los cultivos transgénicos:

Los cultivos transgénicos contribuyen a la sostenibilidad y el desarrollo agropecuario mundial, a la seguridad y autosuficiencia en alimentos, forraje y fibras. Los cultivos transgénicos son una de las tantas herramientas biotecnológicas a servicio de la humanidad, con gran potencial para mitigar los problemas que le aquejan. (p. 40) 


\section{La voz de los movimientos}

Aunque en este trabajo se ha presentado una visión desde el mundo académico -porque este sector fue el convocado a debatir por el presidente de la República- consideramos que mucho más importante ha sido la participación y el accionar de los movimientos sociales, que se han pronunciado en contra de los transgénicos aún antes del proceso constitucional. De hecho, la declaración del Ecuador Libre de Transgénicos fue el resultado de una década de acciones y reflexiones de las organizaciones y movimientos sociales del país, que se inició en 1998, cuando la empresa Monsanto anunció su intención de introducir algodón transgénico.

Aun cuando las aspiraciones de Monsanto no se concretaron, las organizaciones estuvieron listas a responder cuando se anunció el ingreso de una donación de 20 mil toneladas de soya transgénica proveniente de Estados Unidos, y cuando se tuvo conocimiento que los programas de asistencia alimentaria incluían soya transgénica importada (Bravo, 2007). Las acciones hechas en torno a estos hechos posicionaron el debate sobre los transgénicos en Ecuador, que antes era inexistente.

Las organizaciones campesinas, indígenas, de consumidores y ecologistas llegaron al proceso constituyentes con una visión muy clara de querer un Ecuador Libre de Transgénico, demanda que fue recibida por un amplio sector de asambleístas.

Dado que fueron las organizaciones sociales las que colocaron las pautas del debate sobre los transgénicos, el eje del debate es de carácter social y económico, antes que argumentos de tipo técnico/molecular. Las tensiones sobre este tema gravitan entre las bondades y las falsas esperanzas de los transgénicos para mejorar la vida de la gente, especialmente de los grupos campesinos.

Sin embargo, hay que señalar que el movimiento por un Ecuador Libre de Transgénicos incluye militantes que venían de una formación académica de excelencia, y esto elevó el nivel del debate, conformándose en un sujeto social bien fundamentado. Un hito importante fue la publicación "100 razones para declarar al Ecuador Libre de Transgénicos"4, trabajado para apoyar el proceso constituyente que condujo a la prohibición de los transgénicos en el país. Con el anuncio del presidente en noviembre del 2012, se convirtió en "350 razones para un Ecuador Libre de Transgénicos” (Bravo y Gálvez, 2014).

4 Compila y traduce artículos científicos a un lenguaje más popular. 
Gran cantidad de militantes por un Ecuador Libre de Transgénicos son un nuevo tipo de personas expertas, formadas al calor de la militancia por un ambiente sano y a favor de la agricultura campesina. Sobre estos grupos, Funtowicz y Ravetz (2000) señalan que, con la cantidad de información que circula en las redes sociales, ahora, más que nunca, la sociedad tiene acceso a información científica y tecnológica, que anteriormente estaba solo destinada a los sujetos "expertos.

Sin embargo, esto no significa que los movimientos acepten solo los argumentos "basados en la ciencia" como se muestra en los pronunciamientos hechos por las organizaciones sociales en la Tabla 3.

Tabla 3

Pronunciamientos de las organizaciones sociales sobre los OGM

\begin{tabular}{|c|c|c|c|}
\hline Sector & $\begin{array}{l}\text { Organización } \\
\text { representativa }\end{array}$ & $\begin{array}{c}\text { Principales argumentos } \\
\text { contra las OGM }\end{array}$ & Publicación \\
\hline \multirow[t]{2}{*}{ Campesino } & $\begin{array}{l}\text { Federación de Centros } \\
\text { Agrícolas del Litoral }\end{array}$ & $\begin{array}{l}\text { Agudizan la crisis campesina. } \\
\text { Ponen en peligro la semilla } \\
\text { nativa. } \\
\text { Afectan a la salud. }\end{array}$ & El Universo (2014) \\
\hline & $\begin{array}{l}\text { Federación de } \\
\text { Organizaciones } \\
\text { Campesinas, Indígenas y } \\
\text { Negras }\end{array}$ & $\begin{array}{l}\text { Atentan contra la soberanía } \\
\text { alimentaria y el Sumak } \\
\text { Kawsay }^{6}\end{array}$ & Ecuador Libre Red (2013) \\
\hline \multirow[t]{2}{*}{ Indígena } & $\begin{array}{l}\text { Ecuarrunari - Federación } \\
\text { de Nacionalidades y } \\
\text { Pueblos Indígenas de la } \\
\text { Sierra Ecuatoriana }\end{array}$ & $\begin{array}{l}\text { Afectan la salud por el } \\
\text { aumento en el uso de } \\
\text { agroquímicos. } \\
\text { Promueven los monocultivos. } \\
\text { Atentan al Sumak Kawsay. } \\
\end{array}$ & Marcha por la vida (2012) \\
\hline & $\begin{array}{l}\text { CONAIE - } \\
\text { Confederación de } \\
\text { Nacionalidades Indígenas } \\
\text { del Ecuador }\end{array}$ & $\begin{array}{l}\text { Ponen en peligro las semillas } \\
\text { nativas. } \\
\text { Crean dependencia a las } \\
\text { empresas. } \\
\text { Perjudican la economía } \\
\text { campesina. }\end{array}$ & Universal (2015) \\
\hline Ecologista & Acción Ecológica & $\begin{array}{l}\text { Impactan la salud, los } \\
\text { sistemas agrícolas, la } \\
\text { biodiversidad, el ambiente. }\end{array}$ & El Universo (2013) \\
\hline Consumidor & $\begin{array}{l}\text { Comisión de } \\
\text { Consumidores de } \\
\text { COPISA }\end{array}$ & $\begin{array}{l}\text { Privilegian la alimentación } \\
\text { animal. Profundizan la crisis } \\
\text { alimentaria. } \\
\text { Afectan a la salud. }\end{array}$ & El Comercio (2013) \\
\hline
\end{tabular}

5 Se han recogidos los pronunciamientos generados en el mismo período (2012 - 2015).

6 Sumak Kawsay significa Buen Vivir. Es un concepto incorporado en la Constitución del Ecuador proveniente del pensamiento andino, y es un llamado a mejorar la relación de los seres humanos entre sí, y con la naturaleza. 
Finalmente es importante señalar que las organizaciones reconocen que hay alternativas en la agroecología, "modelo basado en la riquísima agrobiodiversidad del Ecuador, reconocido... por sus efectos positivos en la producción alimentaria, en la reducción de la pobreza y en la mitigación al cambio climático" (Colectivo Agroecológico, 2012, p. 40).

\section{Conclusiones}

Como sucede en otras partes del mundo, el debate sobre los transgénicos en el Ecuador está muy polarizado entre quienes defienden un país libre de semillas y cultivos transgénicos y los grupos que se oponen a la prohibición. Mientras los primeros privilegian aspectos socioeconómico y complementan su argumentación con evidencias científicas, los últimos sobredimensionan el peso de la ciencia en el proceso de toma de decisiones.

Otro ángulo de esa polarización se refleja en que, aun cuando cada vez con más frecuencia se publican trabajos científicos independientes robustos que muestran los impactos de los cultivos transgénicos, estos son desdeñados, como sucedió con el estudio publicado en el artículo de Gilles-Eric Séralini y sus colegas (2012), el mismo que luego de una larga polémica tuvo que ser retirado por sus autores.

Tanto en el Ecuador como en otras partes del mundo, algunos sectores explican la gran oposición que hay a los cultivos transgénicos, al desconocimiento que tiene las sociedad sobre la ciencia en la que se sustenta la ingeniería genética, dada su complejidad, y a la falta de involucramiento de los grupos científicos en comunicar y explicar sus beneficios (Cell Press, 2015).

En el debate que se ha dado en el Ecuador en torno a este tema, podemos ver que las principales tensiones, las que más preocupan a la sociedad, están relacionadas con el control que tienen las empresas sobre las semillas transgénicas, y sus efectos en la soberanía alimentaria; así como aspectos relacionados con los posibles impactos en la salud. Estos argumentos fueron lo suficientemente fuertes como para conseguir movilizar a las organizaciones sociales para que se declare al país "libre de cultivos y semillas transgénicas".

El futuro de esta declaración dependerá de las relaciones de poder que atraviesa esta problemática; del peso de la industria en determinar las prioridades sobre ciencia y tecnología, y de la correlación de fuerzas en el seno de las organizaciones sociales. 
Si el Ecuador logra mantenerse como un país libre de semillas y cultivos transgénicos, será el resultado de los equilibrios que se den en dichas relaciones de poder.

\section{Referencias}

Bravo, Elizabeth. (2007). Soya transgénica y ayuda alimentaria. En Rulli, Javiera (Comp.), Repúblicas unidas de la soja. Realidades sobre la producción de soja en América del Sur (pp. 87 - 98). GRR.

BravoElizabeth.(2012).Ecuador:LostransgénicosenlaconsultadelSENACYT. Línea de Fuego. Recuperado de http://lalineadefuego.info/2012/12/10/ los-transgenicos-en-la-consulta-del-senacyt-elizabeth-bravo/

Bravo Elizabeth y Gálvez Elena. (2014). 365 razones para un Ecuador Libre de Transgénicos. Quito: Abya Yala - IEETM.

Breilh, Jaime. (2008). La ciencia por contrato. La relación ciencia y poder. En Ciencia, Tecnología y Sociedad en la Nueva Constitución. Instituto de Estudios Ecologistas del Tercer Mundo. Quito.

Carrera, Javier. (2015). Los transgénicos, en debate. La Barra Espaciadora. 12 de enero 2015. Recuperada de http://labarraespaciadora.com/ pulso/9051/

Cell Press. (2015). Psycology of the appeal of being anti-GMO. Science News. Science Dialy 24 de abril 2015. Recuperado de www.sciencedaily.com/ releases/2015/04/150424105348.htm

Constitución de la República del Ecuador. (2008).

Colectivo Agroecológico. (2012). Agrobiotecnología: Las voces opuestas. Revista Gestión, 217, 38-43.

Cuvi Nicolás. (2014). Hegemonías culturales e impertinencias tecnológicas: Reflexiones en torno de la potencial introducción de transgénicos en el agro ecuatoriano. En Alberto Acosta y Esperanza Martínez (Comps.), Transgénicos inconciencia de la ciencia (pp. 55 - 85). Quito: Abya Yala.

El Comercio. (2012). Correa dice que prohibición constitucional de transgénicos es un "error". 27 de septiembre 2012. Recuperado de http://www. elcomercio.com/actualidad/politica/correa-dice-que-prohibicionconstitucional.html. 
Ecuador Inmediato. (2013). Los alimentos transgénicos deberán ser etiquetados. Recuperado de http://ecuadorinmediato.com/index.php? module $=$ Noticias \&func=news_user_ view\&id=2818748731\&umt=hoy_quito_alimentos_transgenicos_deberan_ser_etiquetados

Ecuador Libre Red. (2012). Resoluciones del XI Congreso Nacional de la FENOCIN. Recuperado de http://ecuadorlibrered.tk/movimientossociales/4428-resoluciones-del-xi-congreso-nacional-de-la-fenocin

Ecuarrunari (2012). Ecuarrunari: Por un Ecuador libre de transgénicos y que se respete la soberanía alimentaria. 9 de octubre. Recuperado de https:// marchaporlavida.wordpress.com/2012/10/25/ecuarunari-por-un-ecuador-libre-de-transgenicos-y-que-se-respete-la-soberania-alimentaria/

El Universo. (2014). Agricultores marcharon en contra de transgénicos. Recuperado de http://www.eluniverso.com/noticias/2014/10/17/ nota/4111766/agricultores-marcharon-contra-transgenicos

El Universo. (2012). Críticas no detienen experimentos para hacer transgénicos. Recuperado de http://www.eluniverso.com/2012/09/30/1/1355/ criticas-detienen-experimentos-hacer-transgenicos.html

Escobar, Julio. (2012). Estado, tendencias y consideraciones institucionales en Ecuador respecto al contexto mundial. IICA. Recuperado de http://legacy.iica.int/Esp/regiones/andina/Ecuador/Publicaciones\%20de\%20 la\%20Oficina/Agrobiotecnolog\%C3\%ADa\%20Ecuador.pdf

Isch, Edgar. (2014). Las nefastas consecuencias de los transgénicos para las políticas públicas. En Alberto Acosta y Esperanza Martínez (Comps.), Transgénicos inconciencia de la ciencia (pp. 103 - 125). Quito: Abya Yala.

León, Xavier. (2014). Transgénicos, agroindustria y soberanía alimentaria. Letras Verdes. Revista Latinoamericana de Estudios Socioambientales, 16, 29-53. Recuperado de http://revistas.flacsoandes.edu.ec/letrasverdes/ article/view/1235

Ortiz Crespo, Gonzalo. (2012). Biotecnología: Las contradicciones del modelo. Revista Gestión, 241, 10 - 13. Tema Central.

Paz y Miño, César. (2013). Transgénicos, una cuestión científica. En Paz y Miño César, Transgénicos, una cuestión científica. Quito: UDLA. 
Paz y Miño, César. (2015). Es necesario romper con los mitos sobre los transgénicos. Recuperado de http://www.pichinchauniversal.com.ec/index. $\mathrm{php} /$ home/noticias-nacionales/item/17728-cesar-paz-y-mino-es-necesario-romper-con-los-mitos-sobre-los-transgenicos

Rodríguez, Javier. (2009). Consecuencias económicas de la soja transgénica. Argentina, 1996-2006. En Los señores de la soya. Buenos Aires: CLACSO.

Santos, Efrén. (2013). Retos de la ingeniería genética del banano en el Ecuador: Resistencia a la sigatoka negra y otras aplicaciones. En Paz y Miño César. Transgénicos, una cuestión científica (pp. 79 - 81). Quito: UDLA.

Secretaría del Ambiente y Desarrollo Sustentable, Subsecretaría de Planificación y Política Ambiental. (2008). El avance de la frontera agropecuaria y sus consecuencias. Buenos Aires. Inédito.

Gilles-Eric Séralini, Clair, Emil, Mesnage, Robin, Gress, Steeve, Defarge, Nicolas, Malatesta, Manuela, Hennequin,Didier, Spirouxde Vendômois, Joël. (2012). Long term toxicity of a Roundup herbicide and a Roundup-tolerant genetically modified maize. Food and Chemical Toxicology, 50, (11), 4221-4231.

Wikileak. (2010). Referencia: 10QUITO54. Origen: Embassy Quito.

Woolfson, Joy. (2013). Biotecnología, organismos genéticamente modificados y bioseguridad. En Paz y Miño César, Transgénicos, una cuestión científica (pp. 75 - 78). Quito: UDLA. 